\title{
Normal obstetric outcome in neurofibromatosis-1 complicating pregnancy
}

\author{
Anitha G.S.*, Manjulatha V.R., Kusuma Naik
}

Department of Obstetrics \& Gynaecology, ESICPGIMS\&R, Bangalore, Karnataka, India

Received: 31 October 2015

Accepted: 12 December 2015

\section{* Correspondence:}

Dr. Anitha G.S.,

E-mail: aninaik85@gmail.com

Copyright: (c) the author(s), publisher and licensee Medip Academy. This is an open-access article distributed under the terms of the Creative Commons Attribution Non-Commercial License, which permits unrestricted non-commercial use, distribution, and reproduction in any medium, provided the original work is properly cited.

\begin{abstract}
Neurofibromatosis (NF), a genetic disorder, has increased risk of obstetric complications as well as aggravation of maternal disease. However, here is a case of Neurofibromatosis associated with normal obstetric outcome despite the aggravation of dermatological lesions and a history of previous pregnancy with anomalous baby.
\end{abstract}

Keywords: Neurofibromatosis, Café au lait spots, Obstetric complication

\section{INTRODUCTION}

Neurofibromatosis (NF) is a distinct genetic disorder with a multitude of clinical manifestations. It is an autosomal dominant condition. The incidence in pregnancy varies from $1 / 5000$ to $1 / 18500$ deliveries. ${ }^{1}$ There are at least 250 unique NF1 mutations reported so far. Specific prenatal diagnosis is only possible through an indirect linkage analysis in families with a previously identified mutation. Approximately $50 \%$ of NF-1 cases result from de novo mutations. ${ }^{2-4}$ To date, only limited information is available on pregnancy in women with NF1. Most of the current obstetric literature indicates that pregnant women with NF1 have increased risk of complications like spontaneous miscarriage, preterm delivery, preeclampsia, intrauterine growth retardation, stillbirths as well as maternal disease aggravation. However, we report a case with normal obstetric outcome despite the aggravation of dermatological lesions of the condition during pregnancy. There is also an obstetric history of previous anomalous baby.

\section{CASE REPORT}

A 25 year old gravida 2, Para 1 woman who had been married for 6 years, presented in the antenatal clinic with
39 weeks pregnancy and labor pains. During her 2nd month of her first pregnancy which was conceived spontaneously after 1 year of marriage, patient developed painless non- itchy nodular skin lesions initially on her upper limbs and gradually progressed to involve her chest, lower limbs, back and last her face. She was diagnosed as neurofibromatosis I. She delivered a male baby of $3.45 \mathrm{~kg}$ birth weight by caesarean section done 4 years ago for breech presentation at 40 weeks gestation. There was increase of lesions in the postnatal period after which they decreased after 4 weeks except on the face and back.

The baby developed seizures at 6 weeks of birth. On evaluation, the baby was found to have arachnoid cyst, café au lait spots and axillary freckling. It was diagnosed with neurofibromatosis I. On subsequent follow up, there was increase in the cyst size leading to hemicerebral atrophy especially in the temporal region. Presently the child has developmental delays (social and motor) and glaucoma of right eye. The child is on conservative treatment.

Her present pregnancy is uneventful except for the increase in the skin lesions. Examination revealed a height of $150 \mathrm{~cm}$, a pulse rate of 84 beats per minute and 
a blood pressure of $120 / 80 \mathrm{~mm} \mathrm{Hg}$ along with mild anemia. There was no pedal edema or varicose veins. Multiple rounded, nontender, nodular lesions of variable sizes characteristic of NF1 were present on the entire body. The cardiovascular system and respiratory system were normal on clinical examination. Abdominal examination revealed a term sized uterus with single fetus in cephalic presentation, adequate liquor and FHR of 132 beats per minute. The cervix was $2 \mathrm{~cm}$ dilated, soft, uneffaced and midposition with intact membranes, vertex presenting at - 2 station in gynecoid pelvis. She underwent ceasarean delivery in view of previous LSCS. She delivered a live male baby weighing $3 \mathrm{~kg}$ with normal apgar scores.

Both the mother and baby fared well in postnatal period.

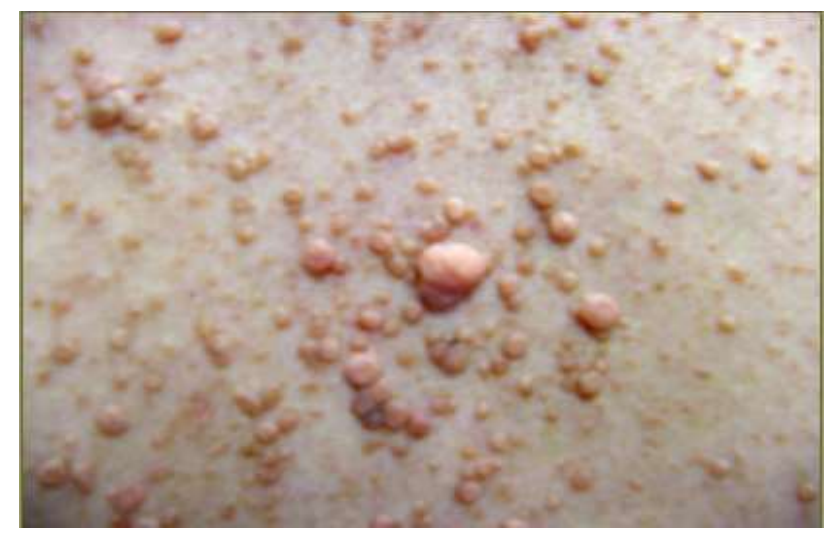

Figure 1: Multiple rounded, nontender, nodular lesions.

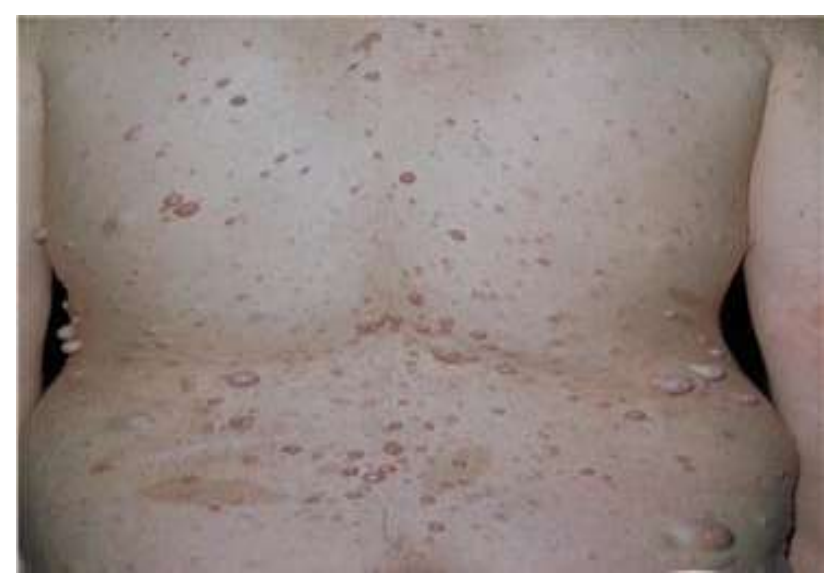

Figure 2: Rounded and nodular lesions on the entire body.

\section{DISCUSSION}

Neurofibromatosis type 1 (NF1, peripheral neurofibromatosis, Von Recklinghausen disease) is one of the most common genetic disorders occurring once in every 4,000 births. It is an autosomal dominant condition which has markedly variable clinical expressions, with manifestations ranging from mild cutaneous lesions like café-au-lait spots and axillary freckling to plexiform neurofibromas, optic gliomas, bony abnormalities, pseudoarthrosis and malignancies. ${ }^{5}$ Some people with NF1 also have other manifestations, such as learning disability and macrocephaly.

Neurofibromatosis includes the more common NF1 caused by mutation in NF1 tumor suppressor gene on chromosome17 and the less frequent NF2 caused by mutation in NF2 gene on chromosome 22. The condition could be inherited from the parents or could occur de novo as a result of spontaneous mutations. Many authors have suggested that pregnant women with NF1 have increased frequency of obstetric complications as well as aggravation of maternal disease thereby placing these women and their fetuses at risk. Spontaneous miscarriage, preterm delivery, preeclamsia, HELLP syndrome, intrauterine growth restriction and stillbirths have been reported. ${ }^{6}$ Pregnancy tends to increase the number and size of cutaneous neurofibromas in women throughout pregnancy, with an apparent decrease in size subsequent to delivery. ${ }^{7}$ Some neurofibromas contain oestrogen receptors, which suggests a relationship between the increase in number and size of neurofibromas and the increase in serum oestrogen levels during pregnancy. ${ }^{8}$

An increased rate of caesarean section is also reported which could be due to fetal distress, malpresentations and cephalopelvic disproportion due to undiagnosed pelvic neurofibromas and pelvic contractures including cases of kyphoscoliosis affecting the lower spine (sequelae of NF1). ${ }^{7}$ Moreover, neurofibromas, the clinical hallmark of NF1 enlarge and many new lesions appear for the first time during pregnancy in many cases as was seen in the present case also. This could be due to hemorrhage within the masses or lysophosphatidic acid (LPA) mediated promotion of F-actin polymerization with increased migration and survival of Schwann cells. ${ }^{9}$ Because of poor pregnancy outcome and possibility of transmission to fetus, Ansari \& Nagamani recommended early termination of pregnancy \& sterilization in these women. ${ }^{10}$ However, a literature search revealed that NF1 may not be associated with significant obstetric complications and may have normal pregnancy outcome. ${ }^{11}$ The present case too, corroborates this view, which in spite of having a positive family history and previous anomalous baby had a normal obstetric outcome in the present pregnancy. Clinicians should bear in mind during counseling as well as management that a normal obstetric outcome could be expected in these women also.

\section{CONCLUSION}

According to literature search revealed that NF1 may not be associated with significant obstetric complications and may have normal pregnancy outcome. The present case too, corroborates this view, which in spite of having a positive family history and previous anomalous baby had 
a normal obstetric outcome in the present pregnancy. Clinicians should bear in mind during counseling as well as management that a normal obstetric outcome could be expected in these women also.

Funding: No funding sources

Conflict of interest: None declared

Ethical approval: Not required

\section{REFERENCES}

1. Oh YM, Koh MS, Yeu JE, Park CS, Cho SJ. A case report of vertebral artery aneurysm and pre eclampsia complicating a pregnancy with neurofibromatosis. Korean J Obstet Gynecol. 2000;43(6):1114-8.

2. Ruggieri M, Huson SM.The clinical and diagnostic implications of mosaicism in the neurofibromatoses. Neurology. 2001;56:1433-43.

3. Colman SD, Rasmussen SA, Ho VT, Abernathy CR, Wallace MR. Somatic mosaicism in a patient with neurofibromatosis type 1. Am J Hum Genet.1996; 58:484-90.

4. Friedman JM. Epidemiology of neurofibromatosis type 1. Am J Med Genet. 1999;(89):1-6.

5. Huson SM, Hughes RAC, editors. The Neurofibromatoses: Pathogenetic and Clinical Overview, London, Chapman \& Hall.1994;160-203.
6. Weissman A, Jakobi P, Zaidise I, Drugan A. Neurofibromatosis and pregnancy. An update. J Reprod Med. 1993;38(11):890-6.

7. Dugoff L, Sujansky E. Neurofibromatosis type 1 and pregnancy. Am J Med Genet. 1996;66:7-10.

8. Leslie KK, White M, Sujanski E. Utilization of polymerase chain reaction (PCR) for identification of estrogen receptors in neurofibromas: potential clinical significance. National Neurofibromatosis Foundation Annual Clinical Care conference. New York: national nf foundation. 1992 case report d rcog 2003. Br J Obstet Gynaecol. 2002;110:530-2.

9. Todd DN, Wenyu M, Shi C et al. Neurofibromin deficient Schwann cells have increased lysophosphatidic acid dependent survival and migration - implications for increased neurofibroma during pregnancy. Glia .2007;55(5):527-36.

10. Ansari AH, Nagamani M. Pregnancy and neurofibromatosis (Von Recklinghausen's disease). Obst \& Gynecology. 1976;47(1):25-9.

11. Terzi YK, Oguzkan-Balci S, Anlar B, Aysun S, Guran S, Ayter S. Reproductive decisions after prenatal diagnosis in neurofibromatosis type 1: importance of genetic counseling. Genet Couns. 2009;20(2):195-202.

Cite this article as: Anitha GS, Manjulatha VR, Naik K. Normal Obstetric Outcome in Neurofibromatosis-1 Complicating Pregnancy. Int J Reprod Contracept Obstet Gynecol 2016;5:246-8. 